\title{
Drivers of photovoltaic uncertainty
}

\section{Energy systems scenarios project a wide range of uncertainty in solar photovoltaic capacity, often thought to stem from techno-economic assumptions. Now research shows that the underlying sources of this uncertainty might be different than expected.}

\section{Sibel Eker}

Climate Interactive, USA

International Institute for Applied Systems Analysis (IIASA), Austria

eker@iiasa.ac.at

To meet the Paris Agreement goal of limiting global warming to $1.5^{\circ} \mathrm{C}$, anthropogenic greenhouse gas emissions should decline to net zero by 2050 . With announcements in late 2020, 127 countries, including the top emitters, are considering or have committed to net-zero targets ${ }^{1}$. There is no silver bullet for climate change mitigation, but renewable energy is expected to be important for net-zero targets. But the potential contribution of renewables is not fully known, and projections of the capacity of solar photovoltaic (PV) technology exhibit particularly large uncertainty. Writing in Nature Climate Change, Marc Jaxa-Rozen and Evelina Trutnevyte ${ }^{4}$ dive into the sources of this uncertainty. They find it is not the modelling or techno-economic assumptions that primarily drive it, but rather who created these scenarios, and when and how. These findings have wide implications not only for mitigation policies, but also for the use of model-based scenarios in the science-policy interface.
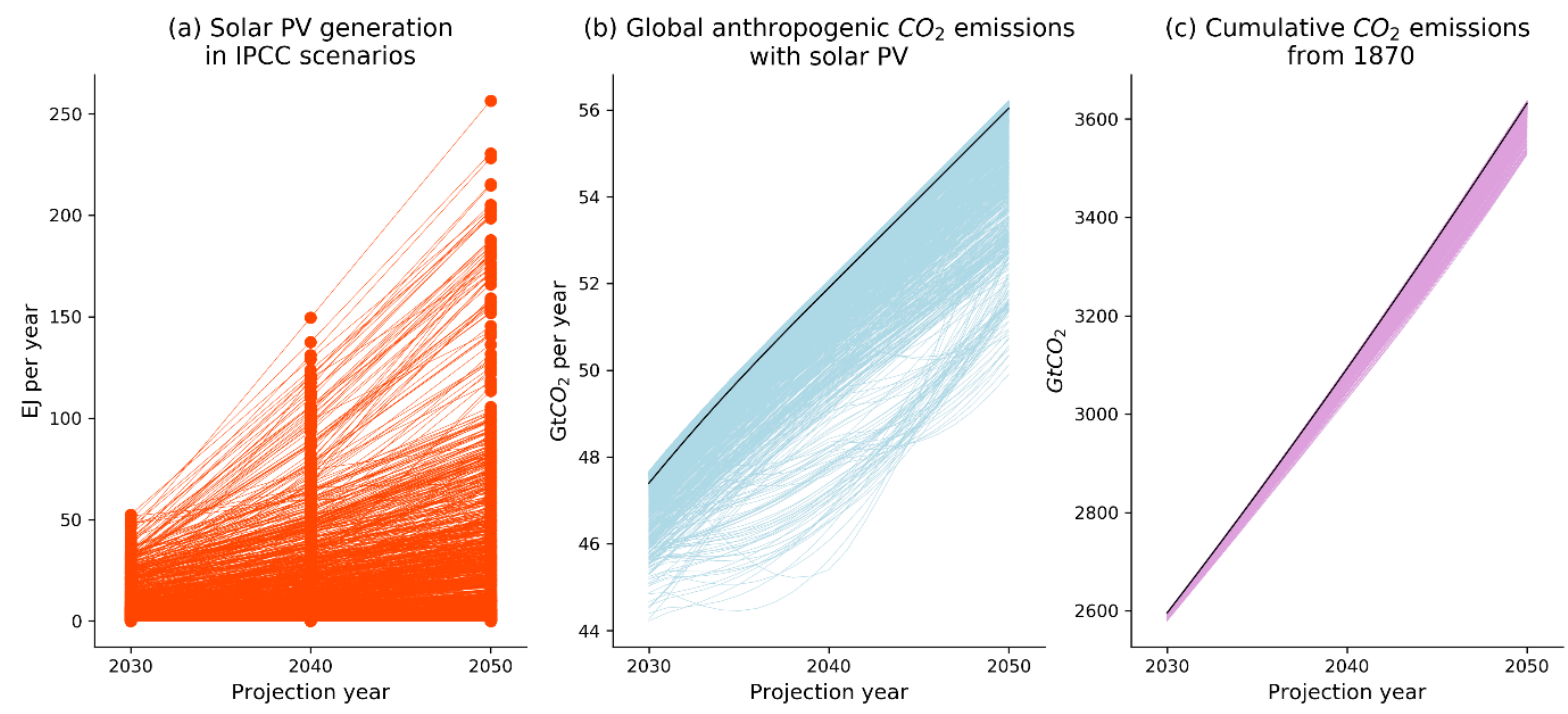

Figure 1: Solar PV generation in IPCC scenarios during 2030-2050 and corresponding emissions. (a) Primary energy demand met by solar energy in 1227 IPCC scenarios compiled from AR5 and SR15 scenario databases ${ }^{5}$, as in Fig. 1a of Jaxa-Rozen and Trutnevyte ${ }^{4}$; (b) Global $\mathrm{CO}_{2}$ emissions when the solar PV generation as in (a) (blue lines), without any changes in climate policy, technology policy, energy efficiency or demand, calculated using the En-ROADS climate solutions simulator ${ }^{6}$. The black line is the baseline (no-policy) scenario where solar PV generation by 2050 reaches 8.6 EJ per year. (c) Cumulative CO2 emissions from the year 1870 corresponding to the effect of only solar PV generation. Solar PV potential shows high uncertainty, and this feeds into uncertainty in annual and accumulate $\mathrm{CO}_{2}$ emissions; understanding what causes this spread is important to more accurately project the future of the global energy system. 
For solar PV technology, which experienced the highest cost reduction (82\%) among renewables in 2010-2019 ${ }^{2}$ and is expected to have the highest electricity generation increase in the coming two decades $^{3}$, the scenarios produced in the last decade project a supply volume varying between almost zero and $300 \mathrm{EJ} / \mathrm{yr}$ in $2050^{4}$. This uncertainty in global solar PV generation corresponds to up to 6.13 $\mathrm{GtCO}_{2} \mathrm{yr}^{-1}$ reduction in annual, and up to $110 \mathrm{GtCO}_{2}$ reduction in cumulative anthropogenic emissions by 2050 (Fig. 1), which might imply substantially different pathways for net-zero efforts.

Model-based scenarios guide climate change research and policymaking by conceptualizing plausible futures and assessing their implications. To avoid overconfidence in their outcomes, scenarios should span a wide range of uncertainties ${ }^{7}$, which arise not merely in the real world context of those scenarios - for example, the technical potential of solar PV - but also due to the boundaries, assumptions, computational implementation, input and processed output data of the models underlying them ${ }^{8}$.

Jaxa-Rozen and Trutnevyte account for these uncertainty sources and more to trace the causes of the wide range of projected solar PV generation out to 2050. They first compile an ensemble of 1,550 scenarios from scientific and grey literature, of which 1,360 are included in the IPCC reports. They tag each scenario with general characteristics, like the type of organization that developed it, the climate policy included, modelling methodology, boundaries or time horizon. They also attach two innovative characteristics to each scenario for further insights into the context: (i) a scenario archetype derived by spectral clustering of the ensemble in terms of key future energy system futures; (ii) a text perspective derived by topic modelling, a text-mining method, of the scenario publications. The authors then employ statistical learning to identify the relative importance of these indicators in explaining projected PV growth.

The results show that policy indicators in the full set of scenarios, such as climate policy, technology policy and scenario archetype, are the most important factors for PV growth projections. Modelling assumptions (like scope, methodology, time horizon and spatial resolution) and contextual factors (like organization type, text perspective and document type) play a less important role. However, in the 190 non-IPCC scenarios, which cover a wider range of PV growth possibilities, model boundaries and the organization type are the most important factors behind PV growth projections. Therefore, to represent the full range of PV growth possibilities, Jaxa-Rozen and Trutnevyte recommend more organizational and model diversity in scenario selection in future IPCC reports.

Two caveats of the study should be noted. First, initial analysis indicates organization type to be a statistically significant factor behind the projected PV growth, with scenarios from renewable energy and consultancy companies reporting the highest capacity growth for solar PV. This initial finding is not echoed by the final comprehensive analysis based on machine learning methods, because the dataset is dominated by IPCC scenarios, and these are limited in their organizational diversity. Second, the study lacks an explicit evaluation of the role of techno-economic assumptions, such as costs. Techno-economic assumptions, though long believed to be the main driver of PV growth projections, are not included in the main analysis of Jaxa-Rozen and Trutnevyte as a scenario indicator, because only 116 of the 1550 analyzed scenarios include explicit cost data. This limitation calls for more transparency on the underlying assumptions from the scenario modelling community, to make full use of the efforts to publicize these scenarios for wider research ${ }^{5}$. 
There is an inclination among decisionmakers to think that more detailed, intricate and accurate models are more valid to support model-based policy analysis'. In other words, the 'science' put into these models determines the scenario projection outcomes. The results of Jaxa-Rozen and Trutnevyte imply that it is not the 'science' that plays the most crucial role, but who developed these scenarios, and when and how. This raises a confrontational question about whether these scenarios are still reliable. The short answer is yes! The long answer is that these results call for a perspective shift that is more inclusive of the diversity and policy-relevance of plausible futures.

The scientific community increasingly acknowledges the importance of incorporating a broader set of futures, uncertainties and perspectives into global scenarios ${ }^{10}$. On this path to more inclusive scenariobased climate change research, methods and tools are needed to deal with a vast and increasing amount of information. Jaxa-Rozen and Trutnevyte ${ }^{4}$ present a novel, multi-method framework to navigate large scenario ensembles and exemplify how to make sense of the vast amount of information contained in them.

\section{Competing interests}

The author declares no competing interests.

\section{References}

1. CAT. Global update: Paris Agreement Turning Point.

https://climateactiontracker.org/publications/global-update-paris-agreement-turning-point/ (2020).

2. IRENA. How Falling Costs Make Renewables a Cost-effective Investment. International Renewable Energy Agency https://www.irena.org/newsroom/articles/2020/Jun/How-Falling-CostsMake-Renewables-a-Cost-effective-Investment.

3. IEA. World Energy Outlook 2020. https://www.iea.org/reports/world-energy-outlook-2020 (2020).

4. Jaxa-Rozen, M. \& Trutnevyte, E. Sources of uncertainty in long-term global scenarios of solar photovoltaic technology. Nat. Clim. Change.

5. Huppmann, D., Rogelj, J., Kriegler, E., Krey, V. \& Riahi, K. A new scenario resource for integrated 1.5 C research. Nat. Clim. Change 8, 1027-1030 (2018).

6. Climate Interactive. En-ROADS Climate Change Solutions Simulator. https://enroads.climateinteractive.org.

7. Schweizer, V. A few scenarios still do not fit all. Nat. Clim. Change 8, 361-362 (2018).

8. Kwakkel, J. H., Walker, W. E. \& Marchau, V. A. Classifying and communicating uncertainties in model-based policy analysis. Int. J. Technol. Policy Manag. 10, 299-315 (2010).

9. Eker, S., Rovenskaya, E., Obersteiner, M. \& Langan, S. Practice and perspectives in the validation of resource management models. Nat. Commun. 9, 5359 (2018).

10. O'Neill, B. C. et al. Achievements and needs for the climate change scenario framework. Nat. Clim. Change 10, 1074-1084 (2020). 